\title{
Socio-Cultural Perceptions and Representations of Dementia in Brazzaville, Republic of Congo: The EDAC Survey
}

\author{
Angélique Faure-Delage ${ }^{a} \quad$ Alain Maxime Mouanga ${ }^{a, d}$ \\ Pascal M'belesso ${ }^{a, f} \quad$ André Tabo $^{a}, g$ Bébène Bandzouzi ${ }^{a}$, $e$ \\ Catherine-Marie Dubreuil $^{a}$ Pierre-Marie Preux ${ }^{a, b}$ \\ Jean-Pierre Clément ${ }^{a, c}$ Philippe Nubukpo ${ }^{a, c}$ \\ aINSERM, UMR 1094, Neuroépidémiologie Tropicale, ${ }^{b} \mathrm{CHU}$ Service de I'Information \\ Médicale et de l'Evaluation, Unité Fonctionnelle de Recherche Clinique et Biostatistique, \\ et ${ }^{\mathrm{C} C e n t r e ~ M e ́ m o i r e ~ d e ~ R e s s o u r c e s ~ e t ~ d e ~ R e c h e r c h e, ~} \mathrm{CH}$ Esquirol Limoges, Limoges, France; \\ Services de ${ }^{d}$ Psychiatrie et ${ }^{e}$ Neurologie, CHU de Brazzaville, Brazzaville, République du \\ Congo; ${ }^{f}$ Service de Neurologie, Hôpital de l'Amitié, et ${ }^{9}$ Service de Psychiatrie, Centre \\ National Hospitalier de Bangui, Bangui, République Centrafricaine
}

\section{Key Words}

Dementia Culture $\cdot$ Social representations - Explanatory Model Interview Catalogue • Central Africa

\begin{abstract}
Background: Dementia will concern more and more people in the developing countries, but the perception people have of dementia in these areas has not yet been studied. Method: During a general population survey (EDAC) carried out in Brazzaville (Republic of Congo), 27 elderly persons suspected of having dementia and 31 of their relatives, 90 cognitively impaired elderly persons and 92 of their relatives, as well as 33 hospital workers were interviewed according to the Explanatory Model Interview Catalogue. Results: Item prominence ratings indicate that the attention was mainly on the emotional and socio-economic consequences (scores $>1.0$ out of 5 points). Ageing and mental stress are the main perceived causes. Hospital workers are more aware of public stigma. Conclusion: The socio-cultural components of the dementia phenomenon have to be taken into account to enforce public health and social measures.
\end{abstract}




\section{Introduction}

Dementia is a major public health problem which is acknowledged worldwide [1]. Criteria outlined in the DSM-IV [2], which is widely used all over the world, give an accurate definition of the biomedical concept of 'dementia'. Etymologically, this term derives from the Latin and means 'derangement of the mind'.

Yet, different communities or social groups do not understand dementia in the same way all over the world [3-8]. The perception of the physical or mental aspects and their explanation imply the use of explanatory models specific to societal or cultural environments $[9,10]$. Social relationships with individuals presenting dementia can be more or less influenced by tolerance or stigmatization [11]. Social support or discrimination follows, which can impact the quality of life of the affected people. However, only few studies have been carried out to collect perceptions and representations of dementia throughout the world, in particular in non-Western countries [12].

In Western countries, some studies have shown that social representations of dementia are rather unfavorable or even depreciative. Health professionals are also concerned by stigmatizing representations and attitudes towards mental illness and dementia [13-16]. But what about Africa? We formulate the hypothesis that the biomedical concept of dementia is unknown to the population, except for among professionals trained in biomedicine. However, the phenomenon is recognized by its symptoms and their impact on everyday life.

This study aims at describing the socio-cultural representations of dementia in Brazzaville, Republic of Congo.

\section{Methods}

\section{Setting and Sampling}

This study was part of the Corus 2 project 'Epidemiology of Dementia in Central Africa' (EDAC). It was conducted in Brazzaville, the capital city of the Republic of Congo. A doorto-door screening survey was carried out to detect demented people aged 65 years or older. All participants underwent cognitive tests (Community Screening Interview for Dementia with questions to the elderly subject and questions to the informant). According to the cognitive scores obtained both at the Community Screening Interview for Dementia $(<25.5 / 30)$ and at the 5-word test $(<10 / 10)$, a group of people were suspected of having dementia (for further details, see [17]). The socio-cultural representations of this sample and of their relatives were collected. A total of 117 out of 148 elderly persons suspected of having dementia were included. Eleven elderly persons were excluded because of their participation in the pretest. Additionally, 20 elderly persons could not be included since they were too weak or ill, or refused to participate. The elderly persons included were not significantly different from the excluded and nonincluded subjects $(n=31)$ in terms of their socio-demographic characteristics and cognitive scores. Dementia cases were confirmed [17], enabling us to divide the elderly people into different groups. Thus, our population sample consisted of 27 demented persons (DPs), 31 of their relatives (DP-Rs), 90 cognitively impaired elderly persons (CIEPs), 92 of their relatives (CIEP-Rs), and 33 hospital workers (HWs) (fig. 1).

\section{Assessment}

This cross-sectional survey was carried out at the participants' homes from February 2009 to March 2009. In addition, for each of the elderly persons, one relative aged $\geq 18$ was asked to participate. HWs were interviewed at Brazzaville's hospital. 
Fig. 1. Flow chart. Socio-cultural representations of dementia in Brazzaville, Republic of Congo, 2009. * Noninclusion criteria included inability to participate, patients lost to follow-up, and patient refusal. ${ }^{* *}$ Exclusion criteria included pretested people and incomplete EMIC.

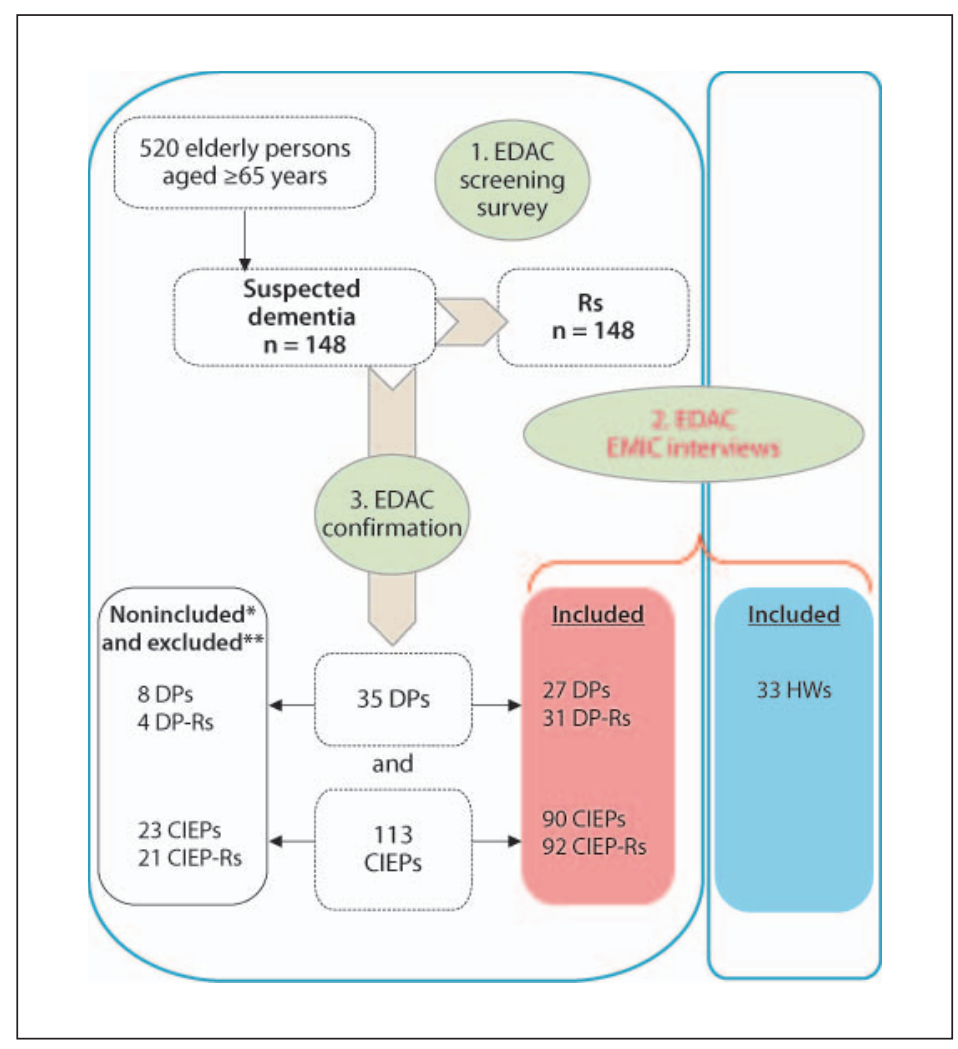

The Explanatory Model Interview Catalogue (EMIC) [18] was used. Five investigators (four residents) were trained to conduct the interviews. The EMIC is a semi-structured guideline with a cross-cultural validity. Its questions and chapters can be adjusted according to a study's objectives. Thus, in order to tailor the instrument to the population (i.e. many elderly people with cognitive impairment), the study theme and the study context (i.e. collection of various points of view, and not only those of outpatients already diagnosed with dementia), 45 questions divided into five chapters were chosen. These focused on socio-demographic information, familarity with the phenomenon, perceived causes, perceived public stigma (scale), and help resources.

The EMIC was adjusted to the study environment. It was translated into the Lingala and the Kituba language. However, no equivalent term to 'dementia' could be found. The expressions 'bokono ya bakoko' in Lingala, and 'kimbevo ya bakoko' in Kituba, which literally mean 'the elderly's disease', were used. The guideline was equally designed to allow participants to speak about dementia in general. Two preliminary questions were added to introduce the discussion about this condition. A brief description of dementia symptoms was given before the interview (elderly persons who forget, lose their bearings, do not recognize their relatives, whose personality is changing, etc.). The questionnaire was pre-tested to check question suitability.

Both quantitative data (scores) and qualitative data (narratives) were analyzed. Perceived public stigma was rated, with a maximal score of 45 points (15 questions rated from 0 to 3). The internal validity of this scale was assessed with Cronbach's $\alpha \leq 0.7$. Dementiarelated symptoms and problems (patterns of distress), perceived causes, and help resources (help seeking) were assessed with prominence ratings, with a maximal score of five points. These ratings are obtained by giving points which quantify each representation and give it 
a weight according to the quality of the answer. In order to do so, a pre-established list of items for each field (patterns of distress, perceived causes, and help seeking) had to be gone through by the investigator during the interview. If an item on the list was reported spontaneously by the respondent, two points were given to this item [18]. Then, the investigator had to suggest all the items not reported spontaneously, and if an item was affirmed, one point was given to this item. For the items neither spontaneously reported (spontaneous) nor affirmed (suggested), the rating was zero points. Finally, the respondent was asked to choose the answer he considered most disturbing or important among all of those (both spontaneous and suggested) he had given. Three points were then added to the one or two points already obtained for this item. Scores out of a maximum of five points were then calculated for each item.

\section{Statistical Analysis}

Numerical data were collected with Excel and narratives with Word. Numerical data were then statistically analyzed with the two softwares StatView 5.0 and SAS 9.1.3 (SAS Institute, Cary, N.C., USA). The texts of the narratives were analyzed with MaxQDA 10 (VERBI software, Berlin, Germany).

The results of the qualitative variables are presented as frequencies and percentages, and those of the quantitative variables are presented as means \pm standard deviation. Comparisons of qualitative variables between two groups of participants were made with $\chi^{2}$ tests or Fisher's exact tests depending on the theoretical numbers. The distributions of the quantitative variables were compared with a Student $t$ test when the variable distribution was normal, as confirmed by the Shapiro-Wilk test. If the variable distribution was not normal, a nonparametric test for unpaired samples, the Wilcoxon test, was used. The linear correlation coefficient $r$ was calculated to evaluate the correlations. The level of significance was set at 0.05 for all analyses.

MaxQDA10 allows to mark text segments with manual codes. Coded segments were classified into categories and subcategories referring to themes identified as interesting by either statistical or lexical analysis.

\section{Results}

\section{Socio-Demographic Data}

The socio-demographic characteristics of the five groups are shown in table 1. DPs $(80.2$ \pm 5.8 years old) were significantly older than CIEPs $(75.7 \pm 6.6$ years old; $p=0.031)$. In each group, the majority of the subjects were women $(\geq 51.5 \%)$. The Christian religion was predominant, in particular Catholicism (45.2-63.3\%). Joining independent churches was more common among DPs (22.2\%) and DP-Rs (35.5\%). Most relatives had attended school (DP-Rs 87.1\% and CIEP-Rs 91.2\%), and most of them had high school education (DP-Rs $54.8 \%$ and CIEP-Rs 58.8\%). In contrast, the elderly people were often illiterate (DPs $77.8 \%$ and CIEPs 83.2\%; nonsignificant (n.s.)). Household incomes were often reported as irregular and not dependent on the elderly persons (DPs $74.1 \%$ and CIEPs $76.7 \%$; n.s.).

\section{Knowledge about the Phenomenon Called 'Dementia'}

The analysis of the narratives generally revealed no knowledge of the concept of dementia used in the biomedical field in the study population, except for among HWs (62.0-71.9\%, vs. $18.2 \%$ for HWs). However, the fact that elderly people forget a lot, lose their bearings, do not recognize their relatives' faces, and behave differently was known, even if it was not really perceived as a disease. For instance, a DP-R said: 'I have never heard of [dementia]. Nev- 
Faure et al.: Social Representations of Dementia in the Republic of Congo

Table 1. Socio-demographic characteristics of the different groups studied (in percentages)

\begin{tabular}{|c|c|c|c|c|c|}
\hline & \multicolumn{2}{|l|}{ Elderly } & \multicolumn{2}{|l|}{ Relatives } & \multirow{2}{*}{$\begin{array}{l}\text { HW } \\
(\mathrm{n}=33)\end{array}$} \\
\hline & $\begin{array}{l}\mathrm{DP} \\
(\mathrm{n}=27)\end{array}$ & $\begin{array}{l}\text { CIEP } \\
(\mathrm{n}=90)\end{array}$ & $\begin{array}{l}\text { DP-R } \\
(\mathrm{n}=31)\end{array}$ & $\begin{array}{l}\text { CIEP-R } \\
(\mathrm{n}=92)\end{array}$ & \\
\hline Females & 74.1 & 75.6 & 77.4 & 68.5 & 51.5 \\
\hline \multicolumn{6}{|l|}{ Religion } \\
\hline Catholic & 63.0 & 63.3 & 45.2 & 56.5 & 54.6 \\
\hline Protestant & 14.8 & 30.0 & 19.4 & 21.7 & 30.3 \\
\hline Independent church & 22.2 & 5.6 & 35.5 & 19.6 & 12.1 \\
\hline Muslim & 0.0 & 1.1 & 0.0 & 1.1 & 3.0 \\
\hline Animist/atheist & 0.0 & 0.0 & 0.0 & 1.1 & 0.0 \\
\hline \multicolumn{6}{|l|}{ Marital status } \\
\hline Married/remarried & 18.5 & 27.8 & 54.8 & 46.2 & 84.9 \\
\hline Widowed & 77.8 & 64.4 & 9.7 & 7.7 & 0.0 \\
\hline Never married/separated & 3.7 & 7.8 & 35.5 & 46.2 & 15.2 \\
\hline Schooling & 29.6 & 27.8 & 87.1 & 91.2 & 100.0 \\
\hline \multicolumn{6}{|l|}{ Education level } \\
\hline Primary school & 7.7 & 19.5 & 16.1 & 15.6 & 0.0 \\
\hline High school & 11.5 & 3.5 & 54.8 & 58.8 & 72.7 \\
\hline University & 3.9 & 0.0 & 16.1 & 16.7 & 27.3 \\
\hline Cannot say & 3.9 & 2.3 & 0.0 & 0.0 & 0.0 \\
\hline Illiteracy & 77.8 & 83.2 & 12.9 & 11.0 & 0.0 \\
\hline Irregular family incomes & 74.1 & 76.7 & 45.2 & 39.1 & 12.1 \\
\hline
\end{tabular}

ertheless, I know that when you get older, you become like a small child. You have problems, worries, and memory loss.'

\section{Recognition of Dementia}

Most of the elderly persons' relatives as well as HWs reported that they had already met or known a person affected with disorders similar to the symptoms of dementia described by the investigator (DP-Rs 71.0\%, CIEP-Rs 75.0\%, and HWs 81.8\%) (table 2). Most of the time (except for HWs), family ties existed with the person met or known. In these cases, $58.1 \%$ of DP-Rs and 31.5\% of CIEP-Rs identified the person that researchers suspected of suffering from dementia (percentages significantly different, $\mathrm{p}=0.009$ ).

On the contrary, only a few of the elderly persons themselves said that they had already met or known a person affected with dementia (DPs 29.6\% and CIEPs 34.4\%). However, in their narratives, $81.5 \%$ of DPs and $57.8 \%$ of CIEPs more or less directly referred to themselves as suffering from symptoms of 'the elderly's disease'. However, the textual analysis emphasizes the fact that, for these persons, it is an umbrella name for different symptoms or conditions, in particular 'fatigue', 'high blood pressure', and rheumatism' ('aching feet', 'pain in the hands', etc.). 'Backache', 'headache', 'sore eyes', and 'stomachache', among others, were equally reported. For example, one DP said: 'I suffer from high blood pressure, I am exhausted, I can no longer walk. I can no longer see, I am diabetic and I have rheumatism. I have a loss of memory, and it is difficult for me to recall things and to recognize people. I also get angry easily.' On the contrary, some of the DPs clearly denied their troubles: 'No, I don't know [this problem], I rarely forget things', 'I still have a good memory, and I don't know any person who suffers from the elderly's disease', or 'I am not [demented], how can I answer all these questions?' 
Table 2. Familiarity with dementia in the different groups studied (in percentages)

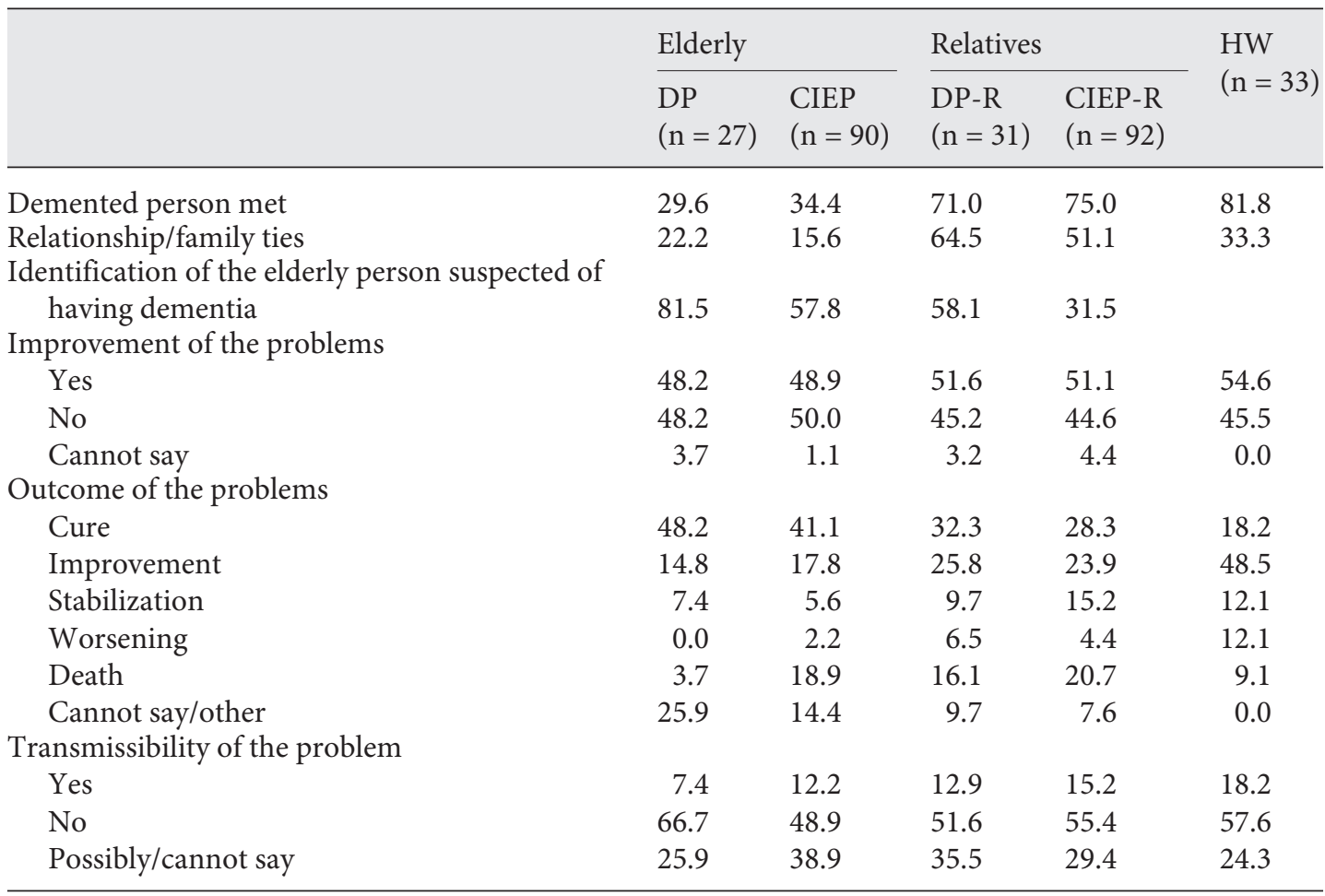

The viewpoints about the improvement in the condition of the persons affected by dementia differed. Almost half of the people in each group thought the symptoms could improve (DPs $48.2 \%$ and HWs 54.6\%), whereas the others hypothesized that no improvement can be obtained. In total, $48.2 \%$ of DPs and $41.1 \%$ of CIEPs believed dementia could be cured, versus only $18.2 \%$ of HWs. Furthermore, $9.1 \%$ of HWs thought the disease was fatal, as did $3.7 \%$ of DPs and $18.9 \%$ of CIEPs. The relatives' views (both DP-Rs and CIEP-Rs) could be divided into the three above-mentioned outcomes (curable: 32.3 and 28.3\%, improvable: 25.8 and $23.9 \%$, and lethal: 16.1 and $20.7 \%$, respectively). In each group, most people thought dementia was not transmittable to other family members (48.9-66.7\%). One elderly person (DP) said: 'No, my children cannot contract this pain-causing disease', and another one (CIEP) supposed: 'I don't think it is contagious, because everybody has their own minds.'

\section{Patterns of Distress}

Patterns of distress consist of both symptoms and problems resulting from dementia. Therefore, the mean numbers of spontaneous or suggested dementia symptoms (out of 12) and related problems (out of 9) were calculated for each group.

It was found that DPs spontaneously reported a slightly higher mean number of symptoms than CIEPs $(2.5 \pm 2.3$ vs. $1.7 \pm 1.5$ out of 12 items; n.s.). However, the sums of spontaneous and suggested symptoms were similar (5.4 \pm 2.4 and $5.0 \pm 2.2$; n.s.). There was no difference in the number of symptoms reported and affirmed between DP-Rs and CIEP-Rs $(6.3 \pm 2.4$ and $6.0 \pm 2.8$; n.s.). On the contrary, HWs gave the highest mean number of symptoms (both spontaneous and suggested). This is significantly different from the results of the group of relatives $(8.6 \pm 2.3$ vs. $6.1 \pm 2.7 ; \mathrm{p}<0.0001)$.

The sums of spontaneous and suggested problems (social, financial, psychological, and other problems) given by DPs and CIEPs were rather similar $(4.3 \pm 1.1$ and $4.7 \pm 1.7$ out of 
Table 3. Mean scores out of 5 highlighting the most reported patterns of distress, perceived causes, and help seeking for dementia (mean \pm standard deviation)

\begin{tabular}{|c|c|c|c|}
\hline Elderly & & Relatives & \\
\hline $\begin{array}{l}\mathrm{DP} \\
(\mathrm{n}=27)\end{array}$ & $\begin{array}{l}\text { CIEP } \\
(\mathrm{n}=90)\end{array}$ & $\begin{array}{l}\text { DP-R } \\
(\mathrm{n}=31)\end{array}$ & $\begin{array}{l}\text { CIEP-R } \\
(\mathrm{n}=92)\end{array}$ \\
\hline
\end{tabular}

Patterns of distress

Sadness, anxiety

Worrying about course of problems

Inability to work

Reduced personal or family income

Recent memory loss

Time and place disorientation

Difficulty moving

Personality change/behavioral disorder

Stigmatization/reduced social status

Perceived causes

Ageing

Mental/emotional stress

Alcohol

Sorcery

Fate, God

Social isolation

Injury, accident, surgery

Poverty

Help seeking

Public hospital

General practitioner

Specialist (doctor)

Religious leader

Social services

Herbal medicine

Traditional healer

Magically revealed herbal medicine

Magico-religious faith healer
Social isolation

State aid/international aid

$\begin{array}{lllll}\mathbf{2 . 0} \pm \mathbf{1 . 5} & 1.7 \pm 1.7 & 1.7 \pm 1.5 & 1.6 \pm 1.4 & 1.2 \pm 1.1 \\ 1.2 \pm 1.3 & \mathbf{1 . 7} \pm \mathbf{1 . 6} & 1.4 \pm 1.4 & \mathbf{1 . 7} \pm \mathbf{1 . 5} & 0.9 \pm 0.7 \\ \mathbf{1 . 7} \pm \mathbf{1 . 6} & \mathbf{1 . 7} \pm \mathbf{1 . 2} & \mathbf{1 . 8} \pm \mathbf{1 . 1} & \mathbf{1 . 9} \pm \mathbf{1 . 3} & \mathbf{1 . 7} \pm \mathbf{1 . 1} \\ 1.0 \pm 1.2 & 1.2 \pm 1.1 & 1.3 \pm 1.1 & \mathbf{1 . 5} \pm \mathbf{1 . 1} & 1.4 \pm 1.1 \\ \mathbf{1 . 7} \pm \mathbf{1 . 2} & 1.6 \pm 1.1 & 1.7 \pm 0.5 & 1.7 \pm 0.9 & \mathbf{2 . 2} \pm \mathbf{1 . 5} \\ 1.0 \pm 1.2 & 0.8 \pm 0.8 & 0.9 \pm 1.2 & 1.0 \pm 0.9 & \mathbf{1 . 6} \pm \mathbf{1 . 1} \\ \mathbf{1 . 0} \pm \mathbf{1 . 1} & 0.9 \pm 0.9 & \mathbf{1 . 1} \pm \mathbf{1 . 1} & 0.8 \pm 1.0 & 0.6 \pm 0.7 \\ 0.9 \pm 0.6 & 0.7 \pm 0.7 & \mathbf{1 . 6} \pm \mathbf{1 . 1} & 1.0 \pm 0.8 & 1.5 \pm 1.1 \\ 0.5 \pm 1.0 & 0.8 \pm 1.3 & 0.9 \pm 1.3 & 0.9 \pm 1.4 & \mathbf{1 . 6} \pm \mathbf{0 . 9} \\ 1.0 \pm 1.4 & 0.8 \pm 1.0 & 0.9 \pm 0.9 & 1.0 \pm 1.1 & 1.1 \pm 0.9 \\ & & & & \\ \mathbf{2 . 4} \pm \mathbf{2 . 1} & \mathbf{2 . 3} \pm \mathbf{1 . 8} & \mathbf{2 . 6} \pm \mathbf{1 . 7} & \mathbf{2 . 7} \pm \mathbf{1 . 7} & \mathbf{2 . 4} \pm \mathbf{1 . 8} \\ 1.1 \pm 0.9 & 1.5 \pm 1.4 & \mathbf{2 . 1} \pm \mathbf{1 . 9} & 1.7 \pm 1.4 & \mathbf{2 . 2} \pm \mathbf{1 . 5} \\ 0.5 \pm 0.9 & 0.8 \pm 0.9 & 0.8 \pm 1.6 & 0.7 \pm 0.7 & \mathbf{1 . 2} \pm \mathbf{0 . 6} \\ \mathbf{0 . 6} \pm \mathbf{0 . 7} & \mathbf{0 . 7} \pm \mathbf{0 . 9} & \mathbf{0 . 5} \pm \mathbf{0 . 6} & \mathbf{0 . 7} \pm \mathbf{0 . 8} & \mathbf{0 . 9} \pm \mathbf{0 . 6} \\ 0.7 \pm 1.4 & \mathbf{1 . 4} \pm \mathbf{1 . 4} & 0.6 \pm 0.8 & 0.5 \pm 0.6 & 0.5 \pm 0.8 \\ 0.3 \pm 0.6 & 0.5 \pm 0.9 & 0.6 \pm 0.6 & 0.9 \pm 1.2 & \mathbf{1 . 3} \pm \mathbf{1 . 0} \\ 0.6 \pm 1.0 & 0.5 \pm 0.5 & 0.8 \pm 0.8 & 0.9 \pm 1.1 & \mathbf{1 . 0} \pm \mathbf{0 . 5} \\ 0.4 \pm 0.9 & 1.0 \pm 1.2 & 0.8 \pm 0.8 & 1.0 \pm 1.2 & \mathbf{1 . 4} \pm \mathbf{1 . 3} \\ & & & & \\ \mathbf{2 . 6} \pm \mathbf{1 . 5} & 2.1 \pm 1.3 & 2.3 \pm 1.7 & 2.0 \pm 1.3 & 2.5 \pm 1.7 \\ 2.5 \pm 1.8 & \mathbf{3 . 0} \pm \mathbf{1 . 9} & 1.5 \pm 1.3 & \mathbf{2 . 3} \pm \mathbf{1 . 6} & 1.4 \pm 1.0 \\ 1.3 \pm 1.4 & 1.2 \pm 1.2 & \mathbf{2 . 7} \pm \mathbf{1 . 9} & 2.0 \pm 1.5 & \mathbf{2 . 8} \pm \mathbf{1 . 5} \\ \mathbf{1 . 2} \pm \mathbf{1 . 2} & \mathbf{1 . 5} \pm \mathbf{1 . 5} & \mathbf{1 . 5} \pm \mathbf{1 . 4} & \mathbf{1 . 4} \pm \mathbf{1 . 4} & \mathbf{1 . 1} \pm \mathbf{0 . 9} \\ 0.8 \pm 0.8 & 0.7 \pm 0.8 & 0.8 \pm 0.4 & \mathbf{1 . 2} \pm \mathbf{1 . 0} & \mathbf{1 . 1} \pm \mathbf{0 . 7} \\ 0.5 \pm 0.5 & 0.6 \pm 0.6 & 0.8 \pm 0.8 & \mathbf{1 . 0} \pm \mathbf{0 . 9} & \mathbf{1 . 1} \pm \mathbf{0 . 5} \\ \mathbf{0 . 9} \pm \mathbf{0 . 8} & 0.8 \pm 0.5 & 0.7 \pm 0.6 & 0.7 \pm 0.6 & 0.6 \pm 0.5 \\ 0.3 \pm 0.5 & \mathbf{0 . 6} \pm \mathbf{0 . 9} & 0.4 \pm 0.6 & 0.4 \pm 0.6 & 0.4 \pm 0.5 \\ 0.7 \pm 0.5 & 0.6 \pm 0.5 & 0.4 \pm 0.5 & \mathbf{0 . 6} \pm \mathbf{0 . 7} & 0.6 \pm 0.5 \\ 0.2 \pm 0.4 & 0.4 \pm 0.7 & 0.1 \pm 0.3 & 0.2 \pm 0.5 & 0.3 \pm 0.6\end{array}$

Figures in bold represent the higher scores among the different groups. Figures in italic represent the scores for which the maximum is lower than 5 .

9 items; n.s.). The same tendency was observed for DP-Rs and CIEP-Rs (5.4 \pm 1.3 and $5.5 \pm$ 1.6; n.s.). HWs reported and affirmed $5.9 \pm 1.7$ problems (vs. $5.5 \pm 2.4$ for all relatives; $\mathrm{p}=$ 0.06 , i.e. n.s.).

Prominence rating scores revealed the elderly persons' sadness and anxiety as well as their concern about their condition as the symptoms and problems which best characterize the dementia phenomenon (table 3). Moreover, the inability to work, the reduced family income notably due to treatment cost (financial burden), and the recent memory loss are also weighty consequences.

Generally speaking, the inability to work and earn a little more money, i.e. to be 'inactive' and 'unproductive', was a problem noticed by all participants (mean scores from 1.7 to 1.9 out of 5 points). However, DPs more often consider sadness and anxiety as the major 
problems ( $2.0 \pm 1.5$ out of 5 points), whereas HWs focus more on memory loss $(2.2 \pm 1.5$ out of 5 points).

Other problems were noticed distinctively by the different groups. For instance, time and place disorientation, stigmatization, personality changes, and, to a lesser extent, social isolation were considered important consequences by HWs, whereas for DP-Rs, difficulty moving, and, more especially, behavioral disorders (irritability, suspicion, regression, etc.) prevailed. Indeed, these troubles lead to a lack of understanding, misunderstandings, and arguments within the family and the neighborhood. One DP-R said: 'We, the family members, are worried; there is a family conflict because of her disease, because through sorcery, my mother has passed her illness onto her grandson who has consequently died. My mother can no longer work, and yet the treatment cost is a heavy financial burden. And, when she thinks too much about her condition, she has hypertension.' Another explained: 'We keep an eye on her; we must always stay with her. We are concerned. She often gets on our nerves. We very often argue.' It is noteworthy that old people, in particular those who were diagnosed with dementia, did not emphasize stigmatization (DPs $0.5 \pm 1.0$ out of 5 points).

\section{Perceived Causes}

The explanatory models of dementia commonly used by people in each groups were ageing or old age (scores from 2.3 to 2.7 out of 5 points) and mental or emotional stress (scores from 1.1 to 2.2 out of 5 points) (table 3). This notion refers to 'think too much', or to 'worry' for someone who is still in shock (because of bereavement, wartime, etc.) or because of life's toughness. An old woman (DP) explained: 'I think the cause is mental stress, because all my life long, I have constantly thought God left me childless.' Another one said: 'Worry over marital problems has given me hypertension and memory troubles.'

Some explanatory models were more specific to certain groups. HWs, more than the persons in the other groups, thought poverty, social isolation, drinking, and, to a lesser extent, corporeal trauma (injury, accident, surgery) are also plausible causes. Fate or God were significantly more often mentioned by CIEPs than by DPs to explain the dementia phenomenon $(\mathrm{p}=0.001)$.

Sorcery remained a noticeable perceived cause for CIEPs and CIEP-Rs $(0.7 \pm 0.9$ and $0.7 \pm 0.8$, with a maximum of 5 points). On the contrary, this was not the case for DPs and DP-Rs, who obtained the lowest mean scores among all groups $(0.6 \pm 0.7$ and $0.5 \pm 0.6$, respectively, out of 5 points, with a maximum of 2 , which means no one in the groups chose this response as the most important cause). HWs scored $0.9 \pm 0.6(0-2)$.

\section{Help Seeking}

The prominence rating scores (table 3 ) indicate people prefer to turn to modern medicine for seeking help when they develop dementia. However, across all groups, the religious leader remains an important help.

Usually, the public hospital is the first reference, particularly for DPs $(2.6 \pm 1.5(1-5))$. General practitioners and specialists are also major help providers. 'The doctor is the most trustworthy person to have a good treatment', a DP summarized. CIEPs and their relatives preferred the general practitioner $(3.0 \pm 1.9(0-5)$ and $2.3 \pm 1.6(0-5)$, respectively), while HWs $(2.8 \pm 1.5(1-5))$ and DP-Rs $(2.7 \pm 1.9(0-5))$ favored the specialist. Finally, religious leaders and religion as a whole are held in high esteem by all groups, especially by DP-Rs (1.5 $\pm 1.4(0-5))$, CIEP-Rs $(1.4 \pm 1.4(0-5))$, and CIEPs $(1.5 \pm 1.5(0-5))$.

More specifically, CIEP-Rs and HWs might advise elderly people to consult social services or to call for state aid or international aid. According to HWs, psychologists could also be helpful (2.0 $\pm 1.2(1-5))$. Apart from religion, traditional and magico-religious help came second (herbal medicine, traditional healer, etc.). Sometimes, other help figures were even 
perceived as really dangerous: 'Mediums destroy the family', one DP-R said. Finally, for some people (here a DP-R), 'there's no help to seek, except from sleeping pills, because we saw a general practitioner, a priest, we prayed in church, we gave herbal infusions [to the ill person], but all in vain. It is just old age.' Moreover, treatments are expensive, and a DP said: 'Considering my ripe old age, I don't believe someone could treat me.'

\section{Public Stigma in Relation to Demented People and Their Close Relatives}

The mean scores of perceived public stigma present some variations among the groups. DP-Rs and CIEP-Rs obtained rather similar mean scores $(12.7 \pm 7.4$ and $12.3 \pm 6.9$ out of 45 points). CIEPs scored higher than DPs (12.4 \pm 7.6$)$ with $13.8 \pm 9.1$ out of 45 points. HWs had the highest mean perceived public stigma score $(16.7 \pm 4.9)$. This score was significantly higher than the scores reported for the relatives ( $\mathrm{p}=0.014$ vs. DP-Rs, and $\mathrm{p}=0.0002 \mathrm{vs}$. CIEP-Rs).

Socio-demographic variables (i.e. sex, illiteracy, marital status, irregular income) could not be added to the multivariate logistic regression model (where only elderly people and relatives were included) because they were not significantly associated with the public stigma scores in the univariate analysis.

\section{Discussion}

As expected, in Brazzaville, the biomedical concept of dementia is generally unknown, except for among health professionals. However, even if no accurate word for the term dementia exists in the local languages, the phenomenon is acknowledged $[5,19,20]$. This is confirmed by the number of dementia symptoms and problems spontaneously reported by each group, and also by the rate of identification of the elderly persons suspected of having dementia (higher for DP-Rs than for CIEP-Rs).

Some common social representations can be identified in relation to symptoms, perceived causes, preferential support, and social tolerance or intolerance towards the persons affected by dementia. People turn their attention first and foremost to the elderly's emotional suffering, the economical consequences for them and their family, and to forgetfullness (a symptom which comes first in the biomedical definition of the disease). According to the participants, old age and mental stress due to a hard life are the main explanations for the condition. Some said 'to fight against this illness, you have to avoid worry'. Modern medicine is widely recognized as the most advisable option, even if for many people religion remains very useful and something they can rely on. According to a DP, the religious leader is able to cure, to bless, and to break the spell'. Generally speaking, people perceive stigmatizing attitudes towards persons affected with dementia disorders; however, solidarity and moral values help to contain this problem.

In addition, more than $80 \%$ of DPs talked about themselves during the interview to explain their notion about the phenomenon of dementia. The number of symptoms which were spontaneously reported by DPs was higher than that reported by CIEPs, but the difference was not significant. Thus, DPs seem to be aware of their troubles and not to be anosognosic. Nevertheless, like DPs, more than half of CIEPs talked about themselves and included many other conditions in their description of their troubles. Without any objective assessment of anosognosia [21], it remains impossible to draw any conclusion about this question and to know if the DPs' perception of public stigma is lower.

As we supposed, according to the participants' narratives, dementia seems to be associated with stigmatization, as are other mental illnesses. DP-Rs reported more perceived public stigma than CIEPs-Rs, even if this difference was not statistically significant. Moreover, 
CIEP-Rs and CIEPs more often referred to sorcery to explain dementia than the other groups, especially DP-Rs. Consequently, we conclude that a relative's closeness to the mentally ill person reduces the relative's anxiety and allows a better understanding of the mentally ill person - a result in line with those found by Angermeyer and Matschinger [22, 23]. Further, the increased contact with health professionals because of the severity of the problems could imply that the explanatory models for dementia of DP-Rs seem to be less influenced by supernatural beliefs. Hence, the biomedical hypothesis would supersede the magico-religious beliefs.

However, the textual analysis indicated that the reported perceived public stigma does not only concern dementia symptoms, but also elderly people in general. As Ihezue and Okpara [24] observed, 'toleration may be less likely when the patient is old, and especially widowed' [25]. The ambivalent relationship with the elderly appears for instance when a relative (DP-R) said that 'when such a person reaches a very old age in your family, you are proud; it is a good thing (...), a blessing, a great blessing from God.' Old age is the symbol of longevity. Knowledge and wisdom are sources of respect, for example when the elderly can 'decide for a problem', or 'give good advice'. Nevertheless, cursing and sorcery are often associated with old people. This implies mistrust and suspicion in the social environment. One DP-R claimed: 'yes, [a demented person is respected]. Because, she's not guilty, she's innocent. She's a senior.' However, according to the same respondent, being in touch with such a person can lead to negative effects 'in relation to African beliefs. She's an old person, so she can cast a spell.' Another DP-R confided: 'When an elderly person is ill, we say it's because she had evil intentions and used sorcery against people who caused her suffering.' If these ideas sound pejorative, they also mean people are not indifferent to the elderly and credit them with some power. Authors like Pollitt [3] explain that the individuals' status, power, and influence, as well as the presence of family support are also relevant factors.

The family remains the cornerstone of solidarity values in Brazzaville. Moral values are essential: 'we're kin; it's my duty to help this person who's in need', one DP-R said. 'In the family, we have to cope with each other, because we're kin. It is difficult at home, but we still have to support the person', another DP-R explained. Marriage and filiations are based on sacred values: 'we get married for better and for worse. (...) She's still my wife; we have to support each other.' The children's respect for their aging parents and the reputation both have in society are also decisive.

We expected health professionals' representations to be different from those of the other groups due to their biomedical training. We hypothesized that their ability to recognize and detect health problems would be determined by their particular perception of the disease [16], i.e. that they would pay more attention to the symptoms. This idea seems to be confirmed by the higher total number of spontaneous and suggested symptoms they gave in comparison to the other groups. Moreover, whereas the emotional consequences of dementia (sadness, anxiety, worrying about the course of the problems) were the most disturbing symptoms for the other groups, the recent memory loss came first in HWs' views. They also focused on time and place disorientation as well as the personality changes. Additionally, their higher mean score of perceived public stigma also tends to suggest their greater awareness of the problem in society.

Beside some common etiological representations, poverty, social isolation, drinking, and corporeal trauma (injury, accident, surgery) are more specifically pointed to by HWs. They also appeared globally more optimistic concerning the improvement of the condition, despite greater skepticism about the possibility of a total recovery from the disease. This confirms, in part, the conclusions of two Australian studies [26, 27], although these were conducted in a high-income country and involved mental health professionals. Indeed, these surveys show HWs are more pessimistic than the general population about the evolution 
of the condition. Also, they are more aware of the discrimination patients have to cope with $[26,27]$.

However, we could observe that the major representations given by the elderly and their relatives (laymen's representations) also prevail among the HWs. Supernatural explanatory models and traditional therapeutic practices and values still exist in their views. Only a few representations are more specifically reported by HWs, especially concerning the symptoms, etiology, and improvement of the disease. In other words, their biomedical training and their knowledge of and closeness to patients would only reach the peripheral system of their representations without reaching the central core (cf. the central core theory [28]). This confirms what other authors have already found $[16,29,30]$, and corroborate that changing minds and, consequently, changing representations down to their central core is very difficult [16].

Despite some strengths (e.g. sample taken from a general population survey, cross-cultural validity of the tool used), this study still has some methodological limitations. For instance, the elderly people were interviewed a few days after medical and neuropsychological examinations. Both their views and their relatives' views might have been influenced by this situation. The idea they had about the investigators might have biased their speech: 'You, the Doctors, are the people who know this disease', one DP said. Moreover, the interviews imply the possibility of a social desirability bias. The method of prominence ratings, in particular, does not take into account this problem and biases such as dissimulation, denial, and taboo. Hence, the weight of supernatural or traditional representations might have been underestimated.

In addition, it was difficult to talk about dementia without referring to it as a disease, though people did not necessarily perceive it as such, as shown before [5]. First, a description of the symptoms had to be given. Thus, the spontaneous report of symptoms might have been biased and might have implied an overestimation of the importance of some representations such as forgetting things. Nevertheless, vignettes are commonly used in this type of survey. Finally, many highlighted differences turned out to be statistically nonsignificant, probably due to the fact that in some of the groups, only few people were included.

\section{Conclusion}

In Brazzaville, despite the fact that the dementia phenomenon is generally unknown in its biomedical sense, dementia is globally acknowledged by the population; however, the condition is still perceived as something which is more normal than pathological. Old age is a source of concern; it reflects the events and difficulties the persons had to cope with in their lives. Memories as well as physical energy decline with time. Nevertheless, daily problems are definitely present, and dependence is a heavy burden. People do report public stigma, the scope of which, however, ranges beyond deviances.

To palliate this misunderstanding, some people still resort to witchcraft and sorcery, which may sometimes lead to disastrous consequences (charges, stoning, etc.). However, this stigmatization is limited by the social structure, in which moral and religious values remain largely and deeply rooted in people's minds. On the whole, the results indicate that modern medicine is widely accepted in Brazzaville. As opposed to traditional medicine or supernatural therapeutic practices, modern medicine appears to be the support people prefer. Nonetheless, people put a lot of faith in those who may help them [10].

Thus, dementia is also a social and cultural phenomenon. The thresholds separating normal ageing, mild dementia, and severe dementia are not necessarily the same as those defined by biomedical criteria [20]. However, social representations of dementia may come 
closer to the biomedical definition, particularly in urban areas, due to gradually absorbed influences. The question is to know how people will make these representations their own representations.

We can conclude that it is really necessary to take into account the perception people have of diseases, and in particular of dementia, before developing public health programs.

\section{Acknowledgements}

The authors thank every person who accepted to participate in the study. They thank the investigators and the staff in Brazzaville, Mr. François Dalmay and Ms. Anaïs Labrunie of the Biostatistics Laboratory and Unit of Biostatistics and Clinical Research in Limoges, Florentina Rafaël, PhD, and Maëlenn Guerchet, PhD, as well as Ms. Sylvie Gauthier who contributed to the development of this study and this paper. Support from the French Ministry of Foreign Affairs (Coopération pour la Recherche Universitaire et Scientifique (CORUS 6024-4) program), from the Fondation pour la Recherche Médicale and from the Doctoral School at University of Limoges is also gratefully acknowledged.

\section{Disclosure Statement}

The authors report no conflict of interest.

\section{References}

1 OMS/WHO: La démence du grand âge. Recherche et action. Rapport d'un groupe scientifique de l'OMS sur la démence sénile. Geneva, WHO, 1986, p 82.

2 American Psychiatric Association: Diagnostic and Statistical Manual of Mental Diseases, ed 4 (text revision). Washington, APP, 2000, p 943.

-3 Pollit PA: Dementia in old age: an anthropological perspective. Psychol Med 1996;26:1061-1074.

-4 Poveda AM: An anthropological perspective of Alzheimer disease. Geriatr Nurs 2003;24:26-31.

5 Enjolras F: Incidence du pronostic sur la construction des modèles explicatifs de la maladie d'Alzheimer à l'île de la Réunion. Sci Soc Santé 2005;23:69-94.

-6 Werner P: Social distance towards a person with Alzheimer's disease. Int J Geriatr Psychiatry 2005; 20:182-188.

>7 Whitehouse PJ, Gaines AD, Lindstrom H, Graham JE: Anthropological contributions to the understanding of age-related cognitive impairment. Lancet Neurol 2005;4:320-326.

-8 Blay SL, Toledo Pisa Peluso E: Public stigma: the community's tolerance of Alzheimer disease. Am J Geriatr Psychiatry 2010;18:163-171.

9 Fassin D: Maladie et médecine; in Fassin D, Jaffré Y (eds): Sociétés, développement et santé. Paris, Ellipses, collection Médecine Tropicale Ed, 1990, pp 38-49.

10 Laplantine F: Anthropologie de la maladie. Etude ethnologique des systèmes de représentations étiologiques et thérapeutiques dans la société occidentale contemporaine. Paris, Payot, 1992, p 411.

11 Goffman E: Stigmate, les usages sociaux des handicaps. Paris, Les éditions de minuit ed, 1963, p 175.

-12 Jeste DV, Alexopoulos GS, Bartels SJ, et al: Consensus statement on the upcoming crisis in geriatric mental health: research agenda for the next two decades. Arch Gen Psychiatry 1999;56:848-853.

-13 Lauber C, Anthony M, Ajdacic-Gross V, Rossler W: What about psychiatrists' attitude to mentally ill people? Eur Psychiatry 2004;19:423-427.

14 INPES: Le regard porté sur la maladie d'Alzheimer. Résultats de trois études pour mieux connaitre la maladie. Paris, 2009, p 11. 
15 INPES: Dossier de presse. Maladie d'Alzheimer: bilan des mesures «santé» et présentation d'études sur la perception de la maladie. Visite au pôle gériatrie de l'hôpital Corentin Celton Issy-Les-Moulineaux (92). Paris, 2009, p 20.

16 Kohl FS: Les représentations sociales de la schizophrénie. Paris, Masson, 2006, p 146.

-17 Guerchet M, M’belesso P, Mouanga A, Bandzouzi B, Tabo A, Houinato D: Prevalence of dementia in elderly living in two cities of central africa: the EDAC survey. Dement Geriatr Cogn Disord 2010;30: 261-268.

18 Weiss M: Explanatory Model Interview Catalogue (EMIC): framework for comparative study of illness. Transcult Psychiatry 1997;34:235-263.

19 Leighton AH, Lambo TA, Hughes CC, et al: Psychiatric Disorder among the Yoruba. A Report from the Cornell Aro Mental Health Research Project in the Western Region, Nigeria. Ithaca, Cornell University Press, 1963.

-20 Herbert CP: Cultural aspects of dementia. Can J Neurol Sci 2001;28(suppl 1):S77-S82.

21 Stirati-Buron S: Anosognosie : définitions, caractéristiques, méthodes d'évaluation, exemple de l'hôpital de jour de neuropsychogériatrie. NPG 2008;8:30-34.

-22 Angermeyer MC, Matschinger H: The effect of personal experience with mental illness on the attitude towards individuals suffering from mental disorders. Soc Psychiatr Epidemiol 1996;31:321-326.

-23 Angermeyer MC, Matschinger H: Social distance towards the mentally ill: results of representative surveys in the Federal Republic of Germany. Psychol Med 1997;27:131-141.

-24 Ihezue UH, Okpara E: Psychiatric disorders of old age in Enugu, Nigeria. Acta Psych Scan 1989;79: 332-337.

25 Ineichen B: The epidemiology of dementia in Africa: a review. Soc Sci Med 2000;50:1673-1677.

-26 Jorm AF, Korten AE, Jacomb PA, Christensen H, Henderson S: Attitudes towards people with a mental disorder: a survey of the Australian public and health professionals. Aust NZ J Psychiatry 1999; 33:77-83.

-27 Hugo M: Mental health professionals' attitudes towards people who have experienced a mental health disorder. J Psychiatr Ment Health Nurs 2001;8:419-425.

28 Abric JC: Les représentations sociales: aspects théoriques; in Abric JC (ed): Pratiques sociales et représentation, ed 3. Paris, PUF, Psychologie sociale, 2003, pp 11-36.

29 Scheid F, Raveau F: Représentations sociales de la maladie mentale. Encycl Med Chir 1991;37725-E$10: 1-5$.

30 Lauber C, Nordt C, Falcato L, Rossler W: Factors influencing social distance toward people with mental illness. Community Ment Health J 2004;40:265-274. 